\title{
Nódulo tiroideo en el niño
}

\author{
Francisca Ugarte $\mathbf{P}^{1,2}$, Hernán García $\mathrm{B}^{3,4}$, \\ Ethel Codner $\mathrm{D}^{2,3}$.
}

\section{Thyroid nodules in children}

\author{
${ }^{1}$ Hospital Exequiel González Cortés, ${ }^{2}$ Clínica Alemana, ${ }^{3}$ Hospital San Borja Arriarán, \\ ${ }^{4}$ Clínica Santa María.
}

$\mathrm{E}_{\mathrm{p}}^{\mathrm{a}}$ n el niño, la presencia de un nódulo tiroideo plantea serias dificultades para establecer el riesgo de malignidad, especialmente si éste es un nódulo tiroideo no palpable (NTNP). No hay cifras de incidencia de NTNP en población pediátrica, así como tampoco estudios de seguimiento de éstos.

El riesgo de malignidad del nódulo tiroideo en el niño es mayor que en el adulto, con frecuencias de 15 a $20 \%$ en nódulos tiroideos palpables en la mayoría de las publicaciones ${ }^{1}$, alcanzando en algunas hasta $50 \%{ }^{2}$; algunas series pediátricas que incluyen NTNP, señalan que $2 / 3$ de los pacientes con NTNP sometidos a cirugía por presentar algún signo sugerente de malignidad, correspondían a cáncer tiroideo ${ }^{3}$.

Datos provenientes de zonas expuestas a radiación por el accidente de Chernobyl, señalan que $48 \%$ de los nódulos tiroideos en niños correspondían a cáncer ${ }^{2}$ y que el porcentaje de malignidad era mayor que en adultos de la misma zona ${ }^{4}$. Por otra parte, el antecedente de irradiación de cabeza, cuello y tórax determinaba, en la década 1950-59, hasta 100\% de cáncer en nódulos tiroideos en niños, cifra que ha descendido hasta $4 \%$ en algunas series ${ }^{5}$.

La presencia de adenopatías cervicales constituye, en un porcentaje considerable, el primer signo de un carcinoma tiroideo en niños, por lo que se suele hacer el diagnóstico por las metástasis ganglionares sin que haya un nódulo tiroideo palpable.

Otros elementos que han sido señalados como factor de riesgo en niños son el sexo masculino y la edad. Si bien hay predominancia del sexo femenino con respecto al masculino en la frecuencia de carcinoma tiroideo (2:1), el riesgo de cáncer en un nódulo es mayor en el sexo masculino. No se disponen de datos respecto del efecto de la edad como factor de riesgo en los nódulos no palpables, sin embargo el carcinoma es especialmente agresivo en menores de 5 años.

En la actualidad, la mayoría de los autores recomiendan como base del estudio, la punción con aguja fina como el único método diagnóstico que orienta respecto de la etiología del nódulo. La alta sensibilidad, especificidad, valor predictivo positivo y negativo de este método en series pediátricas $3,6,7$, la convierte en una técnica altamente recomendable. En nuestro medio son pocos los centros en que se dispone de esta técnica en niños y su utilidad en nódulos tiroideos no palpables en el niño no ha sido establecida.

Considerando el mayor riesgo de cáncer en nódulos tiroideos en el niño, la escasa información disponible en la literatura y la falta de datos anamnésticos y signos clínicos que permitan defi-

Después de la presentación de estas conclusiones en el XII Congreso Chileno de Endocrinología, la rama de endocrinología pediátrica de la Sociedad Chilena de Endocrinología manifestó su inquietud acerca de este problema en los niños. Esto motivó una revisión cuyas conclusiones resumimos a continuación. 
nir la naturaleza de un nódulo tiroideo, se debe realizar un acucioso estudio destinado a evaluar el riesgo de malignidad en el nódulo encontrado pero en muchos casos deberá llegarse a la cirugía.

En base a lo revisado, este grupo recomienda los siguiente:

Frente a un nódulo tiroideo no palpable menor a $1 \mathrm{~cm}$, se puede realizar un seguimiento clínico y ecográfico cada 4 a 6 meses, que permita tempranamente detectar crecimiento del nódulo o aparición de factores de riesgo; si el nódulo es no palpable pero mayor de $1 \mathrm{~cm}$ y no existen factores de riesgo, se puede mantener una conducta expectante con seguimiento clínico y ecográfico.

Por otra parte, si se trata de un nódulo no palpable, mayor de $1 \mathrm{~cm}$, asociado a factores de

\section{REFERENCIAS}

1. Lugo-Vicente H, Ortiz V, Irizarry H, Camps JI, Pagán V. Pediatric thyroid nodules: Management in the era of fine needle aspiration. J Pediatr Surg 1998; 33: 1302-5.

2. Elisei R, Romei C, Vorontsova T, Cosci B, VeremeYCHIK V, KuCHINSKAYA E ET AL. RET/PTC rearrangements in thyroid nodules: Studies in irradiated and nor irradiated, malignant and benign thyroid lesions in children and adults. J Clin Endocrinol Metab 2001; 86: 3211-6.

3. Corrias A, Einaudi S, Chiorboli E, Weber G, Crino A, ANDREo M ET AL. Accuracy of fine needle aspiration biopsy of thyroid nodules detecting malignancy in childhood. J Clin Endocrinol Metab 2001; 86: 4644-8. riesgo, se recomienda la punción con aguja fina dirigida bajo ecografía. En centros en que no se dispone de esta técnica en forma rutinaria debiera derivarse a los pacientes a otros centros y si esto no es posible, deberá plantearse la cirugía para permitir el diagnóstico anatomopatológico del nódulo.

En los nódulos quísticos puros, no palpables, la punción evacuadora con aguja fina pueden constituir una eficiente medida terapéutica y permitir una orientación diagnóstica por citología.

La recomendación antes expuesta requerirá de estudios poblacionales de incidencia de nódulos tiroideos no palpables en población pediátrica, así como de estudios de seguimiento clínico y ecográfico, que confirmen su utilidad en la práctica clínica o bien determinen modificaciones en base a nuevas evidencias científicas.

4. Bongarzone I, Fugazzola L, Vigneri P, Mariani L, MondeLuni P, PACINI F ET aL. Age related activation of the tyrosine kinase receptor proto-oncogene ret and ntrk 1 in papillary thyroid carcinoma. J Clin Endocrinol Metab 1996; 81: 2006-9.

5. De Groot LJ. Clinical review 2: diagnostic approach and management of patients exposed to irradiation to the thyroid. J Clin Endocrinol Metab 1989; 69: 925-8.

6. ARdA IS, Y ILDIRIM S, Firat S. Fine needle aspiration biopsy of thyroid nodules. Arch Dis Child 2001; 85: 313-7.

7. RaAb S, Silvermen JF, Elsheikh TM, Thomas PA, WAKELY PE. Pediatric thyroid nodules: disease demographics and clinical management as determined by fine needle aspiration biopsy. Pediatrics 1995; 95: 46-9. 